\title{
Property of zinc oxide (Zno) nanostructures potential for biomedical system and its common growth mechanism
}

\begin{abstract}
Zinc Oxide $(\mathrm{ZnO})$ nanomaterials have received broad attention thanks to their distinguished performance in electronics, optics and photonics. Due to the novel applications in optoelectronics, sensors, transducers and biomedical sciences, $\mathrm{ZnO}$ materials have become a leading edge in nanotechnology. Therefore, the properties of $\mathrm{ZnO}$ nanostructures potential for applying in biotechnology are marked along with the relevant common growth mechanism aim to provide the vital information about the growing field related to nano- $\mathrm{ZnO}$ in the biomedical system with environmental friendly nature and biocompatibility.
\end{abstract}

Keywords: nanostructures, nanoparticles, nanowires, nanorods, growth mechanism, biomedical system.
Volume 2 Issue 5 - 2017

\section{Kelvii Wei Guo}

Department of Mechanical and Biomedical Engineering, City University of Hong Kong, Hong Kong

Correspondence: Kelvii Wei Guo, Department of Mechanical and Biomedical Engineering, City University of Hong Kong, 83 Tat Chee Avenue, Kowloon Tong, Kowloon, Hong Kong, Tel 852 3442 4621, Email Kelviiguo@yahoo.com

Received: September 20, 2016 | Published: April 04, 2017
Abbreviations: PL, photoluminescence; PLE, photoluminescence excitation; PVP, polyvinylpyrrolidone; MOCVD, metal organic chemical vapor deposition; VLS, vapor-liquid-solid; $\mathrm{ZnO}$, zinc oxide

\section{Introduction}

To date, zinc oxide $(\mathrm{ZnO})$ has been a crucially versatile material in nanotechnology applications. It is well known that $\mathrm{ZnO}$ has a wide band gap $(3.37 \mathrm{eV})$ compound semiconductor attractively suitable for short wavelength optoelectronic applications ${ }^{1,2}$ and its high exciton binding energy $(60 \mathrm{meV})$ ensure efficient excitonic emission at room temperature, which already has been reported in published literature with disordered nanoparticles and thin films. ${ }^{3,4}$ Also, $\mathrm{ZnO}$ is transparent to visible light and can be made highly conductive by doping. ${ }^{5-7}$ Moreover, due to its unique characteristics of crystal structure, the lack of a symmetry center in wurtzite structure and large electromechanical coupling result in strong piezoelectric and pyroelectric properties and show predominant applications in mechanical actuators and piezoelectric sensors, ${ }^{8-10}$ chemical sensors ${ }^{11,12}$ and solar cells..$^{13,14}$

\section{Methods}

\section{Wurtzite ZnO}

Wurtzite $\mathrm{ZnO}$ has a hexagonal structure (space group $\mathrm{C} 6 \mathrm{mc}$ ) with lattice parameters $a=0.3296$ and $c=0.52065 \mathrm{~nm}$. The structure of $\mathrm{ZnO}$ can be simply described as a number of alternating planes composed of tetrahedrally coordinated $\mathrm{O}^{2-}$ and $\mathrm{Zn}^{2+}$ ions, stacked alternately along $c$-axis as shown in Figure $1 .{ }^{15}$ The tetrahedral coordination in $\mathrm{ZnO}$ results in non-central symmetric structure and consequently piezoelectricity. More important characteristic of $\mathrm{ZnO}$ is its polar surfaces. The most common polar surface is the basal plane. The oppositely charged ions produce positively charged $\mathrm{Zn}$ (0001) and negatively charged O-(000-1) surfaces resulted in a normal dipole moment and spontaneous polarization along the $c$-axis with a divergence in surface energy. To maintain a stable structure, the polar surfaces generally have facets or exhibit massive surface reconstructions, but $\mathrm{ZnO} \pm(0001)$ are exceptions: they are atomically flat, stable and without reconstruction. ${ }^{16}$ Efforts to understand the superior stability of the $\mathrm{ZnO} \pm(0001)$ polar surfaces are at the forefront of research in today's surface physics. ${ }^{17,18}$ The other two most commonly observed facets for $\mathrm{ZnO}$ are $\{2-1-10\}$ and $\{01-10\}$, which have non-polar surfaces and lower energy than the $\{0001\}$ facets.

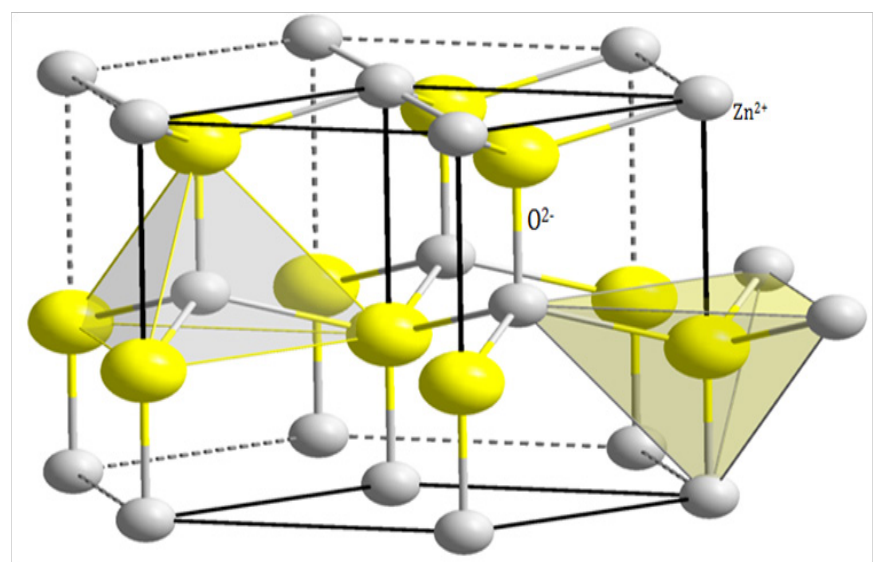

Figure I Wurtzite structure of $\mathrm{ZnO} .^{15}$

\section{ZnO growth}

For $\mathrm{ZnO}$, there are three types of fast growth directions: $<2-1$ $10>( \pm[2-1-10], \pm[-12-10], \pm[-1-120]) ;<01-10>( \pm[01-10], \pm[10-$ $10], \pm[1-100])$ and $\pm[0001]$. $\mathrm{ZnO}$ exhibits a wide range of novel structures that can be grown by tuning the growth rates along these directions on the basis of its polar surfaces. A crystal has different kinetic parameters for different crystal planes, which are emphasized under controlled growth conditions. After nucleation and incubation, a crystallite will commonly grow into a 3D object with well-defined, low index crystallographic faces. Figure 2 shows a few typical $\mathrm{ZnO}$ growth morphologies of $1 \mathrm{D}$ nanostructure. ${ }^{19}$ These structures tend to maximize the areas of the $\{2-1-10\}$ and $\{01-10\}$ facets due to the lower energy. It shall be noted that planar defects and twins are 
observed occasionally parallel to the (0001) plane and dislocations are rarely seen.

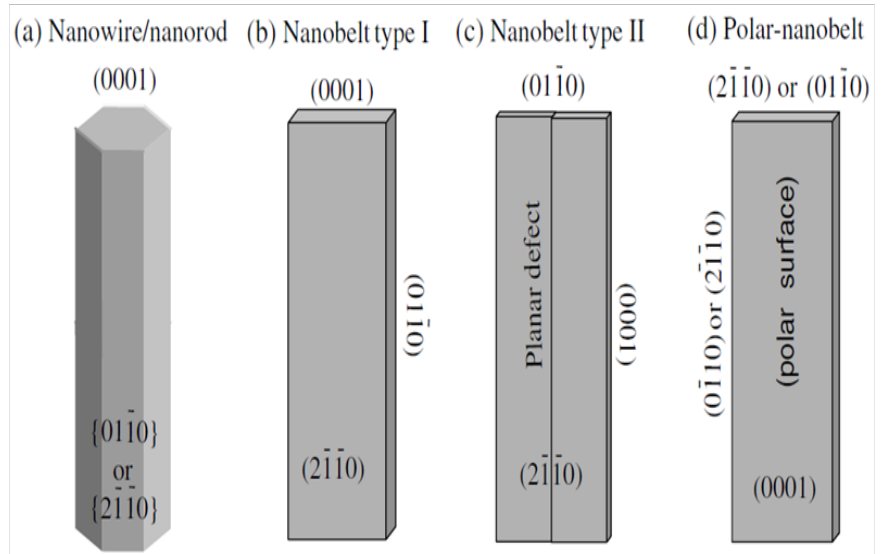

Figure 2 Typical growth morphologies of one-dimensional $\mathrm{ZnO}$ nanostructures and the corresponding facets. ${ }^{19}$

\section{Discussion}

\section{Property of ZnO nanostructures}

Due to the quantum size effect, increasing band gap energy of $1 \mathrm{D} \mathrm{ZnO}$ and nanoparticles can be proved by its photoluminescence property. ${ }^{20-22}$ X-ray absorption spectroscopy and scanning photoelectron microscopy reveal the enhancement of surface states with the downsizing of $\mathrm{ZnO}$ nanorods. ${ }^{23-25}$ Furthermore, the carrier concentration in 1D systems can be significantly affected by the surface states. ${ }^{26,27}$ Therefore, study of the properties of individual $\mathrm{ZnO}$ nanostructures is fundamentally essential to future innovative design of functional nanoscale devices.

Field emission property: The electric field emission from vertically aligned $\mathrm{ZnO}$ nanowires/nanorods has been extensively investigated for these years. One-dimensional (1D) nanomaterials with sharp tip are promising candidates for electron field emission thanks to their natural property from the geometry. Several groups have been reported the field emission properties from vertically aligned $\mathrm{ZnO}$ nanoneedles and nanowires. ${ }^{28-32}$ Results show that turn-on field was found to be $\sim 18 \mathrm{~V} / \mathrm{mm}$ at a current density of $0.01 \mathrm{~mA} / \mathrm{cm}^{2}$ and the emission current could reach $0.1 \mathrm{~mA} / \mathrm{cm}^{2}$ at $24 \mathrm{~V} / \mathrm{mm}$. The better results for $\mathrm{ZnO}$ nanowires synthesized at low temperature were obtained with the turn-on field of $6 \mathrm{~V} / \mathrm{mm}$ at the current density of $0.1 \mathrm{~mA} / \mathrm{cm}^{2}$ and the emission current reached $1 \mathrm{~mA} / \mathrm{cm}^{2}$ at $11 \mathrm{~V} / \mathrm{mm}$, which could provide sufficient brightness as flat panel display. More compellingly, in the electron emission from $\mathrm{ZnO}$ nanotetrapod, a low turn-on field of $1.6 \mathrm{~V} / \mathrm{mm}$ can be realized at a current density of $1 \mathrm{~mA}$ $\mathrm{cm}^{2}$. This improved emission performance was attributed to the higher aspect ratio of tetrapod structure than that of nanowires. ${ }^{33-36}$

Luminescence properties: $\mathrm{ZnO}$ exhibits a direct band gap of $3.37 \mathrm{eV}$ at room temperature with a large exciton binding energy of $60 \mathrm{meV}$. Compare to other wide band gap materials (eg. GaN, 25meV), ${ }^{37,38}$ $\mathrm{ZnO}$ has much stronger exciton binding energy. The efficient exciton emission at room temperature can be easily triggered under low excitation energy because thermal energy of $\mathrm{ZnO}$ at room temperature is $26 \mathrm{meV}$. As a consequence, $\mathrm{ZnO}$ is recognized as a promising photonic material in the blue-UV region. Single crystalline $\mathrm{ZnO}$ nanowires have been synthesized using high temperature VLS (vapor liquid solid) growth methods. Room temperature UV lasing in those well-aligned
$\mathrm{ZnO}$ nanowires has been gained successfully. Results show that there are three emitting bands in PL (Photoluminescence) spectra of $\mathrm{ZnO}$ nanorods measured with the fluorescence at an excitation wavelength of $325 \mathrm{~nm}$ at room temperature, including a strong ultraviolet emission at around $386 \mathrm{~nm}$ and a very weak blue bane $(440 \pm 480 \mathrm{~nm})$ as well as an almost negligible green band $(510 \pm 580 \mathrm{~nm}) .{ }^{39-41}$ For $\mathrm{ZnO}$ nanoparticles, the broad emission band located on the visible range is more obvious than that of the nanorod structure. There is also a PLE (Photoluminescence excitation) spectrum located on the UV region with a maximum intensity wavelength of $370 \mathrm{~nm}$. It illustrates that the $\mathrm{UV}$ emission of $\mathrm{ZnO}$ is contributing to the near band edge emission while the green band emission corresponds to the surface defect. It demonstrates that oxygen vacancies are responsible for the green luminescence in $\mathrm{ZnO}$. Oxygen vacancies occur in three different charge states: the neutral oxygen vacancy $\left(\mathrm{V}^{0}{ }_{\mathrm{O}}\right)$, the singly ionized oxygen vacancy $\left(\mathrm{V}^{*}{ }_{0}\right)$ and the doubly ionized oxygen vacancy $\left(\mathrm{V}^{* *}{ }_{0}\right)$, for which only $\mathrm{V}^{*}{ }_{\mathrm{O}}$ can act as the so-called luminescent centers. ${ }^{42-45}$

\section{ZnO nanostructures}

Up to now, one-dimensional (1D) $\mathrm{ZnO}$ nanostructures have been considered to be one of the most important nanomaterials for fabricating nanodevices with applications in optics, electronics, mechanics and biomedical sciences, especially in the system of bioimaging/biosensor and drug/gene delivery.

ZnO nanoparticles: $\mathrm{ZnO}$ nanoparticles have received attractive and intensive attention for recent years because of its unique optical properties. Nano $\mathrm{ZnO}$ crystals show a compelling and convincing luminescence behavior in the visible region. Meanwhile, the emission wavelengths can be tuned by changing the nanoparticles size. More attractively, $\mathrm{ZnO}$ is a promising candidate for the environmental friendly nature and biocompatibility in the bio-medical system, especially for bio-imaging. ${ }^{40,46,47}$ Also, the exceptional optical and electrical properties of $\mathrm{ZnO}$ nanoparticles may arise from the confinement of excitons and phonons in nanostructures in three dimensions. Although it is reported that the Bohr exciton radius of $\mathrm{ZnO}$ is about $2.34 \mathrm{~nm}$, the size-dependent optical property (band gap variation) of $\mathrm{ZnO}$ nanoparticles, for the ones which are much larger than the quantum confinement size, are still be investigated to the large scale. ${ }^{48,49}$ In the past decades, various methods have been employed to produce photoluminescence $\mathrm{ZnO}$ nanoparticles. ${ }^{50-53}$ Depending on the fabrication techniques and the surface quality of $\mathrm{ZnO}$ nanoparticles, the origin of UV photoluminescence in $\mathrm{ZnO}$ nanoparticles is either recombination of confined excitons or surface-bound ionized acceptor-exciton complexes. Furthermore, more and more unique behaviors are continuously being explored. However, colloidal $\mathrm{ZnO}$ nanocrystals obtained from sol-gel route tend to aggregate due to their surface energy. As a result, such nanocrystals are unstable in aqueous dispersion during storage. To stabilize $\mathrm{ZnO}$ nanoparticles with surface modifications effective in stabling luminescent $\mathrm{ZnO}$ colloids and often well dispersed in organic solvents, various capping agents, such as amines, long chain aliphatic thiols and Polyvinylpyrrolidone (PVP), have been employed. ${ }^{54-58}$ Nevertheless, the majority of bio-analyses require water-dispersible materials and in this regard, synthesis of water-stable $\mathrm{ZnO}$ nanoparticles with emission in visible region is still needed to investigate further.

ZnO nanowires and nanorod: Since the successful growth of aligned $\mathrm{ZnO}$ nanowires on a single-crystal substrate, a system essentially useful for vertical device fabrication has been found. As a result, great interest in acquiring more control over the alignments, 
including supporting substrates, distribution of nanowires and density of nanowires, to maximally meet the requirements of nanodevices has been inspired. ${ }^{59,60}$

\section{Mechanism of common ZnO nanostructures growth}

Aligned growth of $\mathrm{ZnO}$ nanowires can be achieved by various methods, such as vapor-liquid-solid (VLS) process. ${ }^{61-63}$ metal-organic chemical vapor deposition (MOCVD), ${ }^{64-67}$ sol-gel process ${ }^{68-70}$ and aqueous chemical growth process. ${ }^{63,71}$ As follows, two commonly used mechanisms are expressed.

Vapor Liquid Solid (VLS) growth mechanism: Vapor liquid solid (VLS) growth process is a commonly used method to synthesize onedimensional nanostructures. ${ }^{72}$ This mechanism was first proposed by Wagner and Ellis in 1964 for the growth of Si whisker. ${ }^{73}$ Results show that $\mathrm{Si}$ whickers with diameters up to micrometer were grown by hydrogen reduction of $\mathrm{SiCl} 4 \mathrm{Au}, \mathrm{Pt}, \mathrm{Ag}, \mathrm{Pd}, \mathrm{Cu}$ and $\mathrm{Ni}$ played the roles as the catalysts in this growing process. In the VLS process, metal catalyst and the desired material vapor form an alloy and liquefy at the reaction temperature. The metal catalyst can be sensibly chosen from the phase diagram by identifying metals in which the nanowires component elements are soluble in the liquid phase but do not form solid compounds more stable than the desired nanowires phase. $\mathrm{Au}, \mathrm{Cu}, \mathrm{Co}, \mathrm{Fe}$ and $\mathrm{Ni}$ are those commonly used catalysts. The function of the catalyst is to form a crystallization site of nanowires. During the nanowires growth process, catalyst and nanowires material form a low melting point eutectic alloy where is a preferential site for absorption of gas-phase reactant, supersaturated and nucleation for crystallization. Nanowire growth follows by the supersaturating and nucleation of liquid alloy and continues as long as the catalyst alloy remains in a liquid state and the reactant is available. The catalyst droplet also determines the diameter and direction of the growing nanowires. Ultimately, the growth terminates when the temperature is below to the eutectic temperature of the catalyst alloy, or the reactant is no longer available. The VLS growth mechanism of $\mathrm{ZnO}$ nanorods is shown schematically in Figure $3 .^{74}$ Based on the relationship among major parts of growth system, a conceptual model has been summarized in Figure 4.

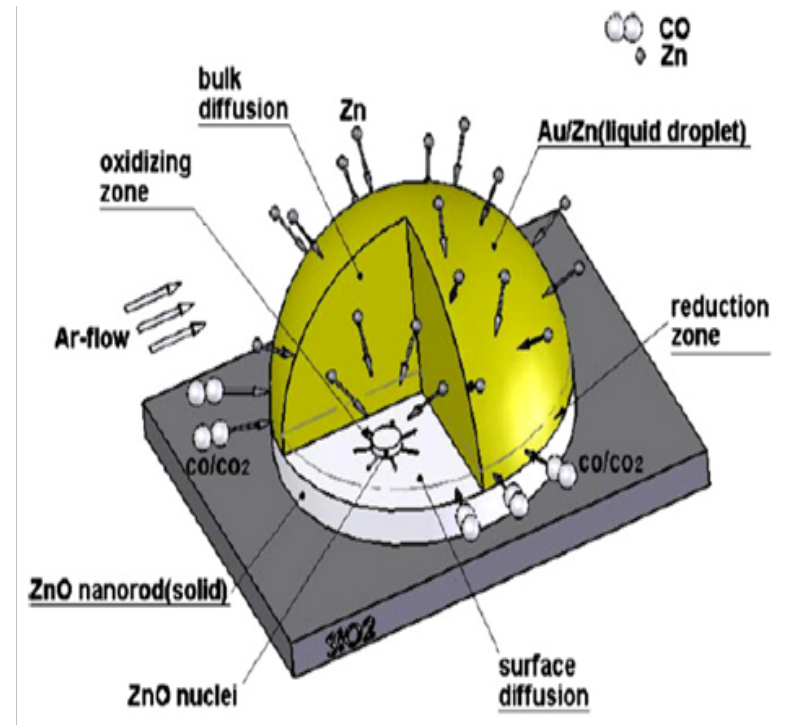

Figure 3 Schematic illustration of nucleation and growth of $\mathrm{ZnO}$ nanorods by the VLS mechanism; $\mathrm{Zn}$ atoms condense and attach to the edges of nuclei and then oxidized by $\mathrm{CO} / \mathrm{CO}_{2}$; lateral growth of $\mathrm{ZnO}$ nuclei causes the completion of one $\mathrm{ZnO}$ monolayer. ${ }^{74}$
Aqueous chemical growth mechanism: Aqueous chemical growth technique has been developed to produce functionalized thin films and coatings of metal oxide materials on various substrates such as amorphous, single crystalline, polycrystalline and flexible substrates. This method is appealing because it is catalyst-free, low cost, low growing temperatures and good potential for scale-up. In addition, this synthetic strategy also does not require any certain template, surfactant membrane or epitaxial substrate to control their orientation. $^{75,76}$ Recently, various nanostructures are synthesized successfully on the basis of aqueous chemical growth method, such as nanorods, ${ }^{77,78}$ nanowires, ${ }^{79,80}$ nanoflowers, ${ }^{81,82}$ nanoneedles,${ }^{83}$ nanoplates, ${ }^{84}$ nanosheets, ${ }^{85}$ nanotowers ${ }^{24}$ and nanotubes. ${ }^{86}$ The synthesis involves the hydrolysis-condensation of hydrated metal ions and complexes (inorganic polymerization) and their hetero nucleation onto substrates. Experimentally, the aqueous chemical growth simply consists of heating an aqueous solution with the metal precursors (salts or complexes) at a given $\mathrm{pH}$ value and ionic strength, in the presence of mild temperatures (below $100^{\circ} \mathrm{C}$ ). This synthetic process requires neither expensive and complicated setups nor hazardous high-pressure containers. Moreover, the organic-free and low temperature approach makes this process safe and environmental friendly. Thanks to the absence of organic solvent, the purity of the as-prepared thin films is substantially improved, that is, the residual salts can be easily removed by water. In most cases, no additional heat or chemical treatments are the superior approach compared to the sol-gel process as well as surfactant, template and membranebased synthesis methods. The utilization of temperature and chemical sensitive substrates required by certain applications is therefore allowed. The processes were focused on controlling the reaction time, concentration of solution, different $\mathrm{pH}$ values and reagents to produce $\mathrm{ZnO}$ nanostructures with different morphologies, especially for the capping reagents, which are remarkable to control the shapes of $\mathrm{ZnO}$ nanostructures successfully.

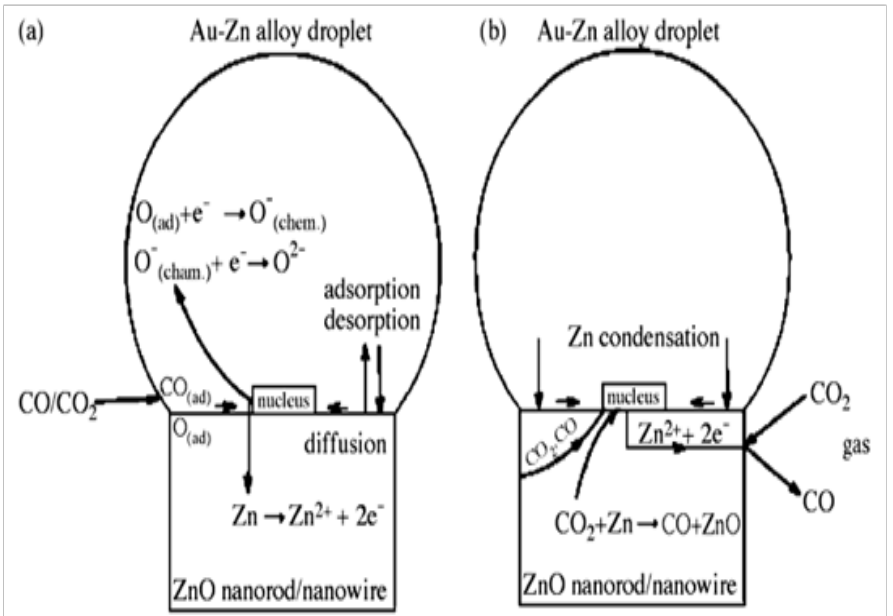

Figure 4 Conceptual model of the VLS growth of the $\mathrm{ZnO}$ nanorods

A. Schematic representation of processes which are involved in the oxidation of $\mathrm{Zn}$ islands and nucleation of $\mathrm{ZnO}$ at the liquid-solid interface and

B. Oxidation of $\mathrm{Zn}$ islands through nanorod. ${ }^{74}$

\section{Conclusion}

The current status of the use of $\mathrm{ZnO}$ nanomaterials for biomedical applications in biomedical imaging, drug delivery, gene delivery and biosensor is flourishing. Consequently, for the environmental friendly nature, greener and simpler methods for $\mathrm{ZnO}$ growth will 
be investigated along with the detailed mechanism. Meanwhile, with the tremendous achievements of $\mathrm{ZnO}$ nanomaterials in biomedical systems coupled with its attractive properties, much research effort will be needed to develop biocompatible/biodegradable $\mathrm{ZnO}$ nanomaterials for the ultimate responsibilities.

\section{Acknowledgements}

None.

\section{Conflict of interest}

The author declares no conflict of interest

\section{Referecnes}

1. Djurišić $\mathrm{AB}, \mathrm{Ng} A M C, C h e n \mathrm{XY}$. ZnO nanostructures for optoelectronics: Material properties and device applications. Progress in Quantum Electronics. 2010;34(4):191-259.

2. Hassan NK, Hashim MR, Al Douri Y. Morphology and optical investigations of $\mathrm{ZnO}$ pyramids and nanoflakes for optoelectronic applications. Optik-International Journal for Light and Electron Optics. 2014;125(11):2560-2564.

3. Pal K, Zhan B, Madhu Mohan MLN, et al. Influence of ZnO nanostructures in liquid crystal interfaces for bistable switching applications. Applied Surface Science. 2015;357(Part B):1499-1510.

4. Kang G, Yoo J, Ahn J, et al. Transparent dielectric nanostructures for efficient light management in optoelectronic applications. Nanotoday. 2015;10(1):22-47.

5. Samadi M, Zirak M, Naseri A, et al. Recent progress on doped $\mathrm{ZnO}$ nanostructures for visible-light photocatalysis. Thin Solid Films. 2016;605:2-19.

6. Othman AA, Ali MA, Ibrahim EMM, et al. Influence of $\mathrm{Cu}$ doping on structural, morphological, photoluminescence, and electrical properties of $\mathrm{ZnO}$ nanostructures synthesized by ice-bath assisted sonochemical method. Journal of Alloys and Compounds. 2016;683:399-411.

7. Yildirim OA, Arslan H, Sönmezoğlu S. Facile synthesis of cobalt-doped zinc oxide thin films for highly efficient visible light photocatalysts. $A p$ plied Surface Science. 2016;390:111-121.

8. Jung DY, Baek SH, Hasan MR, Performance-enhanced $\mathrm{ZnO}$ nanorod-based piezoelectric nanogenerators on double-sided stainless steel foil. Journal of Alloys and Compounds. 2015;641:163-169.

9. Yadav H, Sinha N, Goel S, et al. Eu-doped ZnO nanoparticles for dielectric, ferroelectric and piezoelectric applications. Journal of Alloys and Compounds. 2016;689:333-341

10. Araneo R, Rinaldi A, Notargiacomo A, et al. Advanced mechanical and electrical characterization of piezoelectric $\mathrm{ZnO}$ nanowires for electro-mechanical modeling of enhanced performance sensors. Sensors and Actuators A: Physical. 2016;244:166-173.

11. Ameen S, Park DR, Akhtar MS, et al. Lotus-leaf like ZnO nanostructures based electrode for the fabrication of ethyl acetate chemical sensor Materials Letters. 2016;164:562-566.

12. Rocha LSR, Foschini CR, Silva CC, et al. Novel ozone gas sensor based on $\mathrm{ZnO}$ nanostructures grown by the microwave-assisted hydrothermal route. Ceramics International. 2016;42(3):4539-4545.

13. Abbasi HY, Habib A, Tanveer M. Synthesis and characterization of nanostructures of $\mathrm{ZnO}$ and $\mathrm{ZnO} /$ Graphene composites for the application in hybrid solar cells. Journal of Alloys and Compounds. 2017;690:21-26.
14. Chava RK, Kang M. Improving the photovoltaic conversion efficiency of $\mathrm{ZnO}$ based dye sensitized solar cells by indium doping. Journal of Alloys and Compounds. 2017;692:67-76.

15. https://en.wikipedia.org/wiki/Zinc_oxide

16. Meyer B, Marx D. Density functional study of the structure and stability of ZnO surfaces. Phys Rev B. 2003;67:035403.

17. Berrezoug HI, Merad AE, Zerga A, et al. Simulation and modeling of structural stability, electronic structure and optical properties of $\mathrm{ZnO}$. Energy Procedia. 2015;74:1517-1524.

18. Abbas KN, Bidin N, Sabry RS, et al. Structures and emission features of high-density $\mathrm{ZnO}$ micro/nanostructure grown by an easy hydrothermal method. Materials Chemistry and Physics. 2016;182:298-307.

19. Wang ZL. Zinc oxide nanostructures: growth, properties and applications. Journal of Physics: Condensed Matter. 2004;16:R829-R885.

20. Liu XY, Cao J, Yang LL, et al. Growth mechanism, optical and photocatalytic properties of $\mathrm{ZnO}$ nanorods@nanoflowers (quantum dots) hybrid nanostructures. Ceramics International. 2015;41(9):12258-12266.

21. Farooqi MMH, Srivastava RK. Enhanced UV-vis photoconductivity and photoluminescence by doping of samarium in $\mathrm{ZnO}$ nanostructures synthesized by solid state reaction method. Optik International Journal for Light and Electron Optics. 2016;127(8):3991-3998.

22. Tereshchenko A, Bechelany M, Viter R, et al. Optical biosensors based on $\mathrm{ZnO}$ nanostructures: advantages and perspectives. A review. Sensors and Actuators B: Chemical. 2016;229:664-677.

23. Brahma S, Huang JL, Liu CP, et al. Low temperature and rapid deposition of $\mathrm{ZnO}$ nanorods on $\mathrm{Si}(100)$ substrate with tunable optical emissions. Materials Chemistry and Physics. 2013;140(2-3):634-642.

24. Sigircik G, Erken O, Tuken T, et al. Electrosynthesis of $\mathrm{ZnO}$ nanorods and nanotowers: Morphology and X-ray Absorption Near Edge Spectroscopy studies. Applied Surface Science. 2015;340:1-8.

25. Mrabet C, Mahdhi N, Boukhachem A, et al. Effects of surface oxygen vacancies content on wettability of zinc oxide nanorods doped with lanthanum. Journal of Alloys and Compounds. 2016;688:122-132.

26. Toubane M, Ighil RT, Bensouici F, et al. Structural, optical and photocatalytic properties of $\mathrm{ZnO}$ nanorods: Effect of aging time and number of layers. Ceramics International. 2016;42(8):9673-9685.

27. Ocakoglu K, Mansour SA, Yildirimcan S, et al. Microwave-assisted hydrothermal synthesis and characterization of $\mathrm{ZnO}$ nanorods. Spectrochimica Acta Part A: Molecular and Biomolecular Spectroscopy. 2015;148:362-368.

28. Kar JP, Lee SW, Lee W, et al. Effect of sputtered films on morphology of vertical aligned $\mathrm{ZnO}$ nanowires. Applied Surface Science. 2008;254(20):6677-6682.

29. Dalui S, Das SN, Roy RK, et al. Aligned zinc oxide nanorods by hybrid wet chemical route and their field emission properties. Thin Solid Films. 2008;516(23):8219-8226.

30. Zhang GH, Wei L, Chen YX, et al. Field emission property of $\mathrm{ZnO}$ nanoneedle arrays with different morphology. Materials Letters. 2013;96:131-134.

31. Khan A, Hussain M, Nur O, et al. Fabrication of zinc oxide nanoneedles on conductive textile for harvesting piezoelectric potential. Chemical Physics Letters. 2014;612:62-67.

32. Zhang ZY, Lv YY, Yan JF, et al. Uniform ZnO nanowire arrays: Hydrothermal synthesis, formation mechanism and field emission performance. Journal of Alloys and Compounds. 2015;650:374-380. 
33. Tawale JS, Dey KK, Pasricha R, et al. Synthesis and characterization of $\mathrm{ZnO}$ tetrapods for optical and antibacterial applications. Thin Solid Films. 2010;519(3):1244-1247.

34. Lee SK, Chen WM, Xing DH, et al. Cathodoluminescence characterization of $\mathrm{ZnO}$ tetrapod structures. Thin Solid Films. 2013;543:114-117.

35. Roy N, Roy A. Growth and temperature dependent photoluminescence characteristics of $\mathrm{ZnO}$ tetrapods. Ceramics International. 2015;41(3):4154-4160.

36. Zhang ZP, Song XM, Chen YC, et al. Controllable preparation of 1-D and dendritic $\mathrm{ZnO}$ nanowires and their large area field-emission properties. Journal of Alloys and Compounds. 2017;690:304-314.

37. Gueddim A, Eloud T, Messikine N, et al. Energy levels and optical properties of GaN spherical quantum dots. Superlattices and Microstructures. 2015;77:124-133.

38. Lee $\mathrm{FW}, \mathrm{Ke} \mathrm{WC}$, Cheng $\mathrm{CH}$, et al. Influence of different aspect ratios on the structural and electrical properties of $\mathrm{GaN}$ thin films grown on nanoscale-patterned sapphire substrates. Applied Surface Science. 2016;375:223-229.

39. Tang ZK, Kawasaki M, Ohtomo A, et al. Self-assembled ZnO nano-crystals and exciton lasing at room temperature. Journal of Crystal Growth. 2006;287(1):169-179.

40. Arya SK, Saha S, Vick JER, et al. Recent advances in $\mathrm{ZnO}$ nanostructures and thin films for biosensor applications: Review. Analytica Chimica Acta. 2012;737:1-21.

41. Rehman N, Mehmood M, Rizwan R, et al. Control of optical properties of $\mathrm{ZnO}$ nanostructures grown by a novel two-step synthesis approach. Chemical Physics Letters. 2014;609:26-32.

42. Leung YH, Chen XY, Ng AMC, et al. Green emission in $\mathrm{ZnO}$ nanostructures-Examination of the roles of oxygen and zinc vacancies. Applied Surface Science. 2013;271:202-209.

43. Wang C, Wu D, Wang PF, et al. Effect of oxygen vacancy on enhanced photocatalytic activity of reduced $\mathrm{ZnO}$ nanorod arrays. Applied Surface Science. 2015;325:112-116.

44. Wang J, Xia Y, Dong Y, et al. Defect-rich ZnO nanosheets of high surface area as an efficient visible-light photocatalyst. Applied Catalysis B. Environmental. 2016;192:8-16.

45. Xu LH, Zheng GG, Wang JF, et al.Stable co-emission of UV, green and red light in $\mathrm{ZnO}$ thin films with rapid annealing treatment. Optik - International Journal for Light and Electron Optics. 2016;127(15):59425949.

46. Gupta H, Paul P, Kumar N. Synthesis and Characterization of DHA/ $\mathrm{ZnO} / \mathrm{ZnFe}_{2} \mathrm{O}_{4}$ Nanostructures for Biomedical Imaging Application. Procedia Materials Science. 2014;5:198-203.

47. Sang CH, Chou SJ, Pan FM, et al. Fluorescence enhancement and multiple protein detection in $\mathrm{ZnO}$ nanostructure microfluidic devices. Biosensors and Bioelectronics. 2016;75:285-292.

48. Repp S, Erdem E. Controlling the exciton energy of zinc oxide ( $\mathrm{ZnO}$ ) quantum dots by changing the confinement conditions. Spectrochimica Acta Part A: Molecular and Biomolecular Spectroscopy. 2016;152:637644.

49. Farooqi MMH, Srivastava RK. Structural, optical and photoconductivity study of $\mathrm{ZnO}$ nanoparticles synthesized by annealing of $\mathrm{ZnS}$ nanoparticles. Journal of Alloys and Compounds. 2017;691:275-286.

50. Chakraborty S, Kumbhakar P. Effect of polyethylene glycol on the particle size and photoluminescence emissions characteristics of chemically synthesized $\mathrm{ZnO}$ nanoparticles. Optics Communications. 2014;318:6166.
51. Pessoni HVS, Maia LJQ, Franco A. Eu-doped ZnO nanoparticles prepared by the combustion reaction method: Structural, photoluminescence and dielectric characterization. Materials Science in Semiconductor Processing. 2015;30:135-141.

52. Raj KP, Sadayandi K. Effect of temperature on structural, optical and photoluminescence studies on $\mathrm{ZnO}$ nanoparticles synthesized by the standard co-precipitation method. Physica B: Condensed Matter. 2016;487:1-7.

53. Kim KM, Kim MK, Paek HJ, et al. Stable fluorescence conjugation of $\mathrm{ZnO}$ nanoparticles and their size dependent cellular uptake. Colloids and Surfaces B: Biointerfaces. 2016;145:870-877.

54. Ábrahám N, Dékány I. Size-dependent photoluminescence properties of bare $\mathrm{ZnO}$ and polyethylene imine stabilized $\mathrm{ZnO}$ nanoparticles and their Langmuir-Blodgett films. Colloids and Surfaces A: Physicochemical and Engineering Aspects. 2010;364(1-3):26-33.

55. Shan GY, Hao HW, Wang XM, et al. The effect of PVP on the formation and optical properties $\mathrm{ZnO} / \mathrm{Ag}$ nanocomposites. Colloids and Surfaces A: Physicochemical and Engineering Aspects. 2012;405:1-5.

56. Navaneethan M, Archana J, Arivanandhan M, et al. Functional properties of amine-passivated $\mathrm{ZnO}$ nanostructures and dye-sensitized solar cell characteristics. Chemical Engineering Journal. 2012;213:70-77.

57. Gurav P, Naik SS, Ansari K, et al. Stable colloidal copper nanoparticles for a nanofluid: Production and application. Colloids and Surfaces A. Physicochemical and Engineering Aspects. 2014;441:589-597.

58. Ramimoghadam D, Bagheri S, Hamid SBA. Stable monodisperse nanomagnetic colloidal suspensions: An overview. Colloids and Surfaces B: Biointerfaces. 2015;133:388-411.

59. Zhao CC, Chen AQ, Ji X, et al. Growth of vertically aligned $\mathrm{ZnO}$ nanowire arrays on ZnO single crystals. Materials Letters. 2015;154:40-43.

60. Murillo GAC, Bojorge CD, Heredia EA, et al. Study of the substrate influence in $\mathrm{ZnO}$ nanowires oriented growth. Procedia Materials Science. 2015;8:630-634

61. Suh DI, Byeon CC, Lee CL. Synthesis and optical characterization of vertically grown $\mathrm{ZnO}$ nanowires in high crystallinity through vapor-liquid-solid growth mechanism. Applied Surface Science. 2010;257(5):1454-1456.

62. Kar JP, Das SN, Choi JH, et al. Growth, modulation and photoresponse characteristics of vertically aligned $\mathrm{ZnO}$ nanowires. Applied Surface Science. 2011;257(11):4973-4977.

63. Amiruddin R, Santhosh Kumar MC. Epitaxial growth of vertically aligned highly conducting $\mathrm{ZnO}$ nanowires by modified aqueous chemical growth process. Ceramics International. 2014;40(7):11283-11290.

64. Lee W, Jeong MC, Myoung JM. Catalyst-free growth of $\mathrm{ZnO}$ nanowires by metal-organic chemical vapour deposition (MOCVD) and thermal evaporation. Acta Materialia. 2004;52(13):3949-3957.

65. Zeng YJ, Ye ZZ, Xu WZ, et al. Well-aligned ZnO nanowires grown on $\mathrm{Si}$ substrate via metal-organic chemical vapor deposition. Applied Surface Science. 2005;250(1-4):280-283.

66. Fragalà ME, Aleeva Y, Malandrino G. Effects of metal-organic chemical vapour deposition grown seed layer on the fabrication of well aligned $\mathrm{ZnO}$ nanorods by chemical bath deposition. Thin Solid Films. 2011;519(22):7694-7701.

67. Biethan JP, Sirkeli VP, Considine L, et al. Photoluminescence study of $\mathrm{ZnO}$ nanostructures grown on silicon by MOCVD. Materials Science and Engineering: B. 2012;177(8):594-599.

68. Kashif M, Ali ME, Ali SMU, et al. Sol-gel synthesis of Pd doped ZnO nanorods for room temperature hydrogen sensing applications. Ceramics International. 2013;39(6):6461-6466. 
69. Kitazawa N, Aono M, Watanabe Y. Growth of vertically aligned one-dimensional $\mathrm{ZnO}$ nanowire arrays on sol-gel derived $\mathrm{ZnO}$ thin films. Journal of Physics and Chemistry of Solids. 2014;75(11):1194-1200.

70. Wang MD, Xing CC, Cao K, et al. Alignment-controlled hydrothermal growth of well-aligned $\mathrm{ZnO}$ nanorod arrays. Journal of Physics and Chemistry of Solids. 2014;75(7):808-817.

71. Amiruddin R, Kumar MCS. Enhanced visible emission from vertically aligned $\mathrm{ZnO}$ nanostructures by aqueous chemical growth process. Journal of Luminescence. 2014;155:149-155.

72. Nebolsin VA, Dunaev AI, Tatarenkov AF, et al. Scenarios of stable vapor $\rightarrow$ liquid droplet $\rightarrow$ solid nanowire growth. Journal of Crystal Growth 2016;450:207-214.

73. Wagner RS, Ellis WC. Vapor-liquid-solid mechanism of single crystal growth. Applied Physics Letters. 1964;4:89.

74. Hejazi SR, Hosseini HRM, Ghamsari MS. The role of reactants and droplet interfaces on nucleation and growth of $\mathrm{ZnO}$ nanorods synthesized by vapor-liquid-solid (VLS) mechanism. Journal of Alloys and Compounds. 2008;455(1-2):353-357.

75. Vayssieres L. Growth of arrayed nanorods and nanowires of $\mathrm{ZnO}$ from aqueous solutions. Advanced Materials. 2003;15(5):464-466.

76. Perillo PM, Atia MN, Rodríguez DF. Effect of the reaction conditions on the formation of the ZnO nanostructures. Physica E. 2017;85:185-192.

77. Strelchuk VV, Nikolenko AS, Kolomys OF, et al. Optical and structural properties of $\mathrm{Mn}$-doped $\mathrm{ZnO}$ nanorods grown by aqueous chemical growth for spintronic applications. Thin Solid Films. 2016;601:22-27.

78. Singh N, Haque FZ. Synthesis of zinc oxide nanoparticles with differen $\mathrm{pH}$ by aqueous solution growth technique. Optik-International Journal for Light and Electron Optics. 2016;127(1):174-177.
79. Chey CO, Nur O, Willander M. Low temperature aqueous chemical growth, structural, and optical properties of $\mathrm{Mn}$-doped $\mathrm{ZnO}$ nanowires. Journal of Crystal Growth. 2013;375:125-130.

80. Bahramian R, Eshghi H, Moshaii A. Influence of annealing temperature on morphological, optical and UV detection properties of $\mathrm{ZnO}$ nanowires grown by chemical bath deposition. Materials \& Design. 2016;107:269-276.

81. Yu HW, Fan HQ, Wang X, et al. Template-free sonochemical synthesis of flower-like ZnO nanostructures. Physics Letters A. 2014;378(45):33153318 .

82. Dalvand R, Mahmud S, Rouhi J. Direct growth of flower-like ZnO nanostructures on porous silicon substrate using a facile low-temperature technique. Materials Letters. 2015;160:444-447.

83. Dalvand R, Mahmud S, Rouhi J, et al. Well-aligned ZnO nanoneedle arrays grown on polycarbonate substrates via electric field-assisted chemical method. Materials Letters. 2015;146:65-68.

84. Zamiri R, Singh B, Bdikin I, et al. Influence of Mg doping on dielectric and optical properties of $\mathrm{ZnO}$ nano-plates prepared by wet chemical method. Solid State Communications. 2014;195:74-79.

85. Rahman MM, Khan SB, Marwani HM, et al. Selective detection of divalent nickel ions based on wet-chemically prepared Cs-doped $\mathrm{ZnO}$ nanosheets. Superlattices and Microstructures. 2014;71:93-104.

86. Acharyya D, Bhattacharyya P. Alcohol sensing performance of $\mathrm{ZnO}$ hexagonal nanotubes at low temperatures: A qualitative understanding. Sensors and Actuators B: Chemical. 2016;228:373-386. 